\title{
Actividad biológica de hongos endófitos presentes en dos plantas medicinales chuquirahua (Chuquiragua jussieui J. F. Gmel) y ñachag (Bidens andicola Kunth)
}

\author{
Ernesto Delgado Fernández I*, Santiago Vásquez Matute, Ximena Icaza Samaniego \\ I Laboratorio de Biotecnología, Campus Juan Lunardi, Universidad Politécnica Salesiana, Paute, Ecuador. \\ * Autor para correspondencia: mdelgado@ups.edu.ec
}

\begin{abstract}
Resumen
La presente es una investigación acerca de la actividad biológica de hongos endófitos aislados de dos plantas consideradas medicinales Chuquiragua jussieui J.F. Gmel y Bidens andicola Kunth, recolectadas en tres zonas diferentes del parque nacional Cajas de Cuenca, Ecuador. Los taxa fúngicos más frecuentes fueron: Alternaria, Fusarium, Nigrospora, Phoma, Coelomycetes, el mayor porcentaje de infestación correspondió a los denominados «Mycelia sterilia» (micelios estériles) siendo de particular interés su actividad antagonista. Se evaluó in vitro, la interacción antagónica de estos hongos endófitos, frente, a hongos fitopatógenos: Botrytis cinerea, Phragmidium disciflorum, Colletotrichum gloesporoides, Oidium Sp. Guignardia citricarpa, Pestalotia Sp. Plasmopara viticola, Pythium Sp.Taphrina deformans, Fumago Sp. Monilia roreri, Ceratocystis fimbriata, Bremia lactucae. Los resultados más prometedores se evidenciaron en aislados de «Mycelia sterilia» (estructuras no esporificantes) con un porcentaje del $89,1 \%$ frente al Colletotrichum gloesporoides agente causal de la antracnosis en el tomate de árbol. Además se hizo el análisis in vitro frente a bacterias fitopatógenas de los géneros: Erwinia Sp.Agrobacterium tumefacens, Pseudomonas Sp. y Xanthomonas Sp. Algunas cepas de hongos endófitos de los taxa mencionados, presentaron actividad antagonista, el objetivo de esta investigación y análisis es determinar los niveles y porcentajes de antagonismo, para el uso de los hongos endófitos en el control de enfermedades fitopatógenas causadas por hongos y bacterias. Los resultados son muy satisfactorios, según lo encontrado.
\end{abstract}

Palabras clave: Hongo endófito, cultivo dual, antagonismo.

\begin{abstract}
The present investigation about the biological activity of isolated endophytic fungi in two plants considered medicinal, Chuquiragua jussieui J.F. Gmel y Bidens Andícola Kunth, collected in three different areas of the Cajas National Park in Cuenca, Ecuador. The most frequent fungi taxa were: Alternaria, Fusarium, Nigrospora, Phoma, Coelomycetes. The highest percentage corresponded to the so-called «Mycelia sterilia» (sterile mycelia), their antagonist activity being of particular interest. The antagonist activity of these endophytic fungi was evaluated in vitro as compared to that of phyto-pathogenic fungi: Botrytis Cinerea, Phragmidium Disciflorum, Colletotrichum Gloesporoides, Oidium Sp. Guignardia Citricarpa, Pestalotia Sp. Plasmopara Vitícola, Pythium Sp. Taphrina Deformans, Fumago Sp. Monilia Roreri, Ceratocystis Fimbriata, Bremia Lactucae. The most promising results were evidenced in isolated "Mycelia sterilia" (non-spore-producing structures) with a percentage of $89,1 \%$ as compared to Colletotrichum Gloesporoides, causal agent of anthracnose in tree tomatoes. Besides, in vitro analysis was conducted for phyto-pathogenic bacteria such as: Erwinia Sp. Agrobacterium Tumefacens, Pseudomonas Sp. y Xanthomonas Sp. Most of the fungi analyzed here showed antagonist activity, including some endophytic fungi of the above-mentioned taxa. The purpose was to determine the levels and percentages of antagonist activity for the use of endophytic fungi in the control of phyto-pathogenic diseases caused by fungi and bacteria. The outcomes of this research are promising in this sense.
\end{abstract}

Key words: endophytic fungi, dual cultivation, antagonism.

La Granja 9(I): 29-43. 2009.

(C) 2009, Universidad Politécnica Salesiana, Ecuador. 


\section{Introducción}

El propósito de esta investigación fue el estudio de una especie de hongos denominados endófitos, aislados de dos plantas, consideradas ancestralmente como medicinales, Chuquiragua jussieui y Bidens andicola Kunth, plantas nativas del Parque Nacional El Cajas en Cuenca, Ecuador. Se pretende determinar la actividad biológica, mediante análisis in vitro utilizando como técnica cultivos duales, se busca, analizar, su interacción antagonista frente a hongos y bacterias fitopatógenas. Para entender la temática necesariamente debemos tener un concepto claro de lo que es un hongo endófito, podemos decir que conceptualmente la palabra endófito se deriva del griego endon cuyo significado es dentro y phyte que significa planta. El primero en definir el término endófito fue De Bary en 1866 aunque, en 197I se definió al endofitismo como el estado de un organismo que vive en el interior de otro, en contraposición a la condición de hepifitismo. $\mathrm{Ca}$ rrol, en 1986, hizo su definición de los hongos endófitos como endosimbiontes y excluyó de este grupo los hongos patógenos y asociaciones de micorrizas. En 1994, Wennstrom no fue el único en polemizar sobre el uso de la palabra y propone una redefinición de endófito: utilizar la definición original, un ser vivo que mora en el organismo interno de otro. Otro concepto nos dice que estos hongos viven asintomáticamente en la planta, la mayor parte de su ciclo vital, tienen esporulación limitada en breves periodos y en algunos casos pueden estimular el desarrollo y la fuerza competitiva del huésped. Wilson, en 1995, hace una revisión sobre el significado del término y define a los hongos endófitos como los que invaden los tejidos de plantas vivas, pueden ser sistémicos, asistémicos ó mutualísticos. En cambio, otros se manifiestan como parásitos o algo similar, pudiendo vivir en la planta durante su ciclo vital o parte de él, esto excluye a las asociaciones de micorrizas, se incluye a hongos que son patógenos que no representan síntomas en el tejido. Dreyfuss afirmó que los hongos endófitos representan la más grande reserva de especie fungina, pero es necesario recordar que es un campo de investigación relativamente nuevo, y que seguramente todos los estudios que se llevan a cabo contribuirán a una mayor comprensión acerca del tema. Se ham realizado muy pocos estudios sobre los hongos endófitos, se han realizado muy pocos, de lo que se conoce, existen trabajos cientíicos en las zonas tropicales (Dreyfuss y Petrini, 1984; Rodrígues y Samuels, 1990; Rodrígues and Samuels, 1992). Debido a la gran biodiversidad, al menos en nuestro país, resulta demasiado extenso el trabajo, pero también se conoce de trabajos que se llevan a cabo en plantas que viven en ambientes extremos, como los desiertos y la Antártica. El conocimiento acerca de los hongos endófitos, permitirá aplicaciones de gran importancia, como el control biológico de plagas y enfermedades, pero también dependerá de la capacidad y el potencial para producir metabolitos secundarios, que pueden ser utilizables en el campo médico, fitopatológico e industrial, cualquiera sea el uso que se pueda dar, son modelos de investigación, de la interacción huésped-parásito y la evolución del sistema natural. Las gramináceas igualmente son objeto de gran estudio, para determinar la causa del impacto ecológico que tiene el huésped sobre la comunidad vegetal. Los primeros estudios en este sentido, se dieron en I94I (Neil, 194I) determinando la asociación entre la Festuca Orundinaceae y el hongo endófito Epichloe typhina y Acremonium coenophialum, desde aquí se parte para futuros estudios en el área, para llegar a determinar la relación hongo-vegetal. En la bibliografía analizada, no se encuentran datos acerca del análisis antagónico in vitro de hongos endófitos de dos plantas Chuquiragua Jussieui y Bidens andicola Kunth, frente a hongos fitopatógenos, hongos endófitos y bacterias fitopatógenas. La presente investigación, se fundamenta en la capacidad antagónica de estos. El problema más grande dentro de patología vegetal, son los hongos. ¿Se podría considerar los hongos endófitos como antagonistas de hongos y bacterias fitopatógenas? Mediante cultivos duales in vitro, se logra determinar los porcentajes de inhibición de los hongos endófitos, con respecto a hongos y bacterias comunes, causantes de enfermedades en diferentes cultivos. Determinar la actividad biológica de los hongos endófitos y estudiar su interacción antagonista frente a hongos fitopatógenos y bacterias, con el propósito de indagar el uso de estos microorganismos para el control biológico de enfermedades fitopatológicas, es el propósito de esta investigación.

\section{Materiales y métodos}

\section{I Área de muestreo}

La investigación, se lleva a cabo en el parque nacional el Cajas, se aislaron hongos endófitos de dos plantas consideradas medicinales Chuquiragua jussieui J.F. Gmel y Bidens andicola Kunth. Para la investigación, se consideran tres zonas: Zona I coordenadas UTM. 17 $696532 \mathrm{E} ; 9692756 \mathrm{~N}$; altitud $3972 \mathrm{msnm}$, coordenadas LAT. LONG. $02^{\circ} 46.70 \mathrm{I}$ S; $079^{\circ} 13.9270$ O; altitud 3972 msnm.; zona 2 coordenadas UTM. 176993 I 3 E; $9691739 \mathrm{~N}$; Altitud $3892 \mathrm{msnm}$, coordenadas LAT. LOG. $02^{\circ} 47.25$ I S; $079^{\circ}$ I 2.424 O;Altitud 3892 MSNM; 
Zona 3 coordenadas UTM. 17700210 E; 9692189 N; Altitud 369l msnm, coordenadas LAT. LONG. $02^{\circ} 47.005 \mathrm{~S} ; 079^{\circ}$ II.942 O; altitud 3693 MSNM.

\subsection{Insolamiento y Taxonomía de hongos endófitos}

\subsection{Esterilización de la muestra}

La esterilización de las muestras, de cualquier parte de la planta, comienza con el lavado en agua corriente, luego se procede a la esterilización superficial siguiendo métodos y recomendaciones establecidas, (Rodríguez, 1992); se consideran partes del vegetal, sanas y libres de enfermedades. Se realizaron inmersiones en etanol $\left(\mathrm{C}_{2} \mathrm{H}_{5} \mathrm{OH}\right)$ al $75 \%$ e hipoclorito de sodio $(\mathrm{NaClO})$ con una concentración del $3,41 \%$ dependiendo del tipo de material vegetal, en este caso, las muestras de Chuquiragua jussieui J.F.Gmel, por disponer de hojas robustas, la esterilización, se realizó con un tiempo de tres minutos en hipoclorito de sodio y un minuto en etanol. Con las muestras de Bidens andicola Kunth, por disponer de hojas y flores sutiles, se tomó en cuenta un tiempo de treinta segundos para el hipoclorito de sodio y treinta segundos para el etanol. Teniendo en cuenta condiciones estériles, se cortan muestras del vegetal de $\left(3-4 \mathrm{~mm}^{2}\right)$ tratando de cortar entre la nervadura central y el borde de la hoja, en el caso del vegetal Chuquiragua jussieui, con respecto a la Bidens andícola, se tomaron muestras de la flor por ser la parte del vegetal considerada con propiedades medicinales, los cortes del vegetal, se inocularon en cajas Petri $(100 \times 15 \mathrm{~mm})$ con Agar extracto de malta, (MEA; Difco). 5 muestras por caja, luego se insolaron en cajas petri de igual tamaño con el objeto de obtener cultivos puros, $y$ finalmente el mismo procedimiento en tubos de ensayo con PDA Difco a pico de clarín, para evitar el desarrollo de bacterias se utilizó cloranfenicol $250 \mathrm{mg} /$ litro. El desarrollo de la colonia fungina, se controla diariamente, con la ayuda de un estéreo microscopio; la identificación y morfometría se lleva a cabo a través de un microscopio, mediante la preparación de placas, utilizando como tinción lacto fenol de Amann o lacto fucsina ácida. El lacto fenol es incoloro y permite ver la coloración propia de los micromicetes, al contrario, la fucsina ácida es un colorante que evidencia más intensamente las características estructurales funginas. La identificación de los hongos y su clasificación se hace por medio de claves y referencias bibliográficas, con la colaboración del Dipartimento di Ecología del Territorio - Universitá di Pavía - Italia. El diseño experimental usado es la prueba chi cuadrado, para determinar los niveles de infestación de hongos endófitos en las tres zonas consideradas.

\subsection{Insolamiento y Taxonomía de Hongos Fitopatógenos} La caracterización de hongos fitopatógenos de mayor incidencia en la zona del austro, como en la región Costa, fue también el propósito de esta investigación, además, aislar e identificar bacterias fitopatógenas asociadas al cultivo del babaco Carica pentagona. La caracterización morfológica se basa principalmente en la estructura, y composición (conidios, conidióforos, etcétera.) (Barnett y Hunter, 1998). Para el aislamiento del patógeno y la caracterización, se toman muestras del vegetal, luego se lavan con agua destilada, se cortan muestras del vegetal afectado por la enfermedad, las muestras se toman del borde de la hoja, en la cámara de flujo laminar, se procede a desinfectar las muestras, con hipoclorito de sodio al $4 \%$, etanol al $75 \%$ por un tiempo variable. Luego, son colocadas en un medio de cultivo para hongos, en este caso se utilizó PDA (Difco) en cajas petri de (100 x $15 \mathrm{~mm}$ ). Se colocaron 5 muestras en cada caja, posteriormente, se hace el control del desarrollo (esporificación), siguiendo el procedimiento detallado anteriormente, el objetivo de este procedimiento, es obtener cultivos puros, en este caso de hongos fitopatógenos que, posteriormente, serán identificados y clasificados taxonómicamente, mediante el uso de un microscopio y la elaboración de placas. La clasificación taxonómica se hace por medio de claves, referencias bibliográficas y manuales de identificación específicos para los géneros en estudio.

\subsection{Valoración in vitro de la actividad de antagonismo} cultivo dual hongo endófito-hongo fitopatógeno.

Para el empleo del test, se parte de cultivos monospóricos, se emplea el método de cultivos duales, con puntales estériles, se toman fragmentos de micelio de 4 a $5 \mathrm{~mm}$ de diámetro, éstos son tomados de los cultivos monospóricos en desarrollo, en un terreno PDA, e inoculados en una cámara de flujo laminar, en cajas petri de $(100 \times 15 \mathrm{~mm})$ que contienen el mismo terreno. Los dos micelios a antagonizar son inoculados a $4 \mathrm{~cm}$ de distancia $(2,5 \mathrm{~cm}$ de distancia del borde de la caja). En cada prueba se lleva una caja de control, que se obtiene del mismo cultivo madre (monospórico), es inoculado sobre PDA a la distancia de $2,5 \mathrm{~cm}$ del borde de la caja petri. Todos los test se llevan a cabo en duplicado, en este caso los cultivos se mantiene a temperatura ambiente y se realizan mediaciones diarias del radio dirigido hacia el centro de la caja. La inibición de los hongos fitopatógenos opuestos a los hongos endófitos se expresa como porcentaje de inhibición del crecimiento radial del micelio. 


\section{Delgado, Vásquez e Icaza}

$$
\text { Inibición }(\%)=100 \times(R-r) / R
$$

Donde $R$ y $r$, respectivamente, son el radio dirigido hacia el centro de la caja en el control y en el cultivo dual (Watanabe, 1980) y propuesto por otros autores (Dalla Valle y D'Aurelio Zechini, 1989; Pearce, 1990; Varese y Luppi-Mosca, 1991).

\subsection{Cultivo dual hongo-bacteria}

La metodología es muy parecida, del margen de colonias funginas en crecimiento sobre terreno PDA, son cortados y retirados, con puntales estériles, discos de micelio de $4 \mathrm{~mm}$ de diámetro, luego son inoculados en cajas de $9 \mathrm{~cm}$ de diámetro que contienen $20 \mathrm{ml}$ del mismo terreno, una distancia de $2,6 \mathrm{~cm}$ del margen de la caja, mientras que a una distancia de $3,7 \mathrm{~cm}$ se inocula una suspensión bactérica de $0,5 \mathrm{ml}$.

\subsection{Análisis microscópico}

Las pruebas duales se completan con el análisis microscópico de fragmentos de micelio de las colonias en contacto y de las áreas marginales, para determinar las posibles alteraciones morfológicas de los microorganismos.

\section{Resultados}

\section{I Taxonomía hongos endófitos}

3. I.I Tasa de infestación "Chuquiragua jussieui"

Los taxa de hongos encontrados en las dos especies de plantas investigadas se reporta por el porcentaje referido a la incidencia del hongo en la planta, se calculó sobre el total de fragmentos de hojas analizados por especie vegetal. Los principales taxa aislados, fueron: Mycelia sterilia (micelios sin fructificaciones), Alternaria, algunos representantes de los Coelomycetes y algunos hongos ambientales comunes (Acremonium, Fusarium, Phoma) algunos hongos aislados se consideran patógenos, nos referimos a los géneros Alternaria y Fusarium, que se reporta , acerca de su patogenicidad en diversos hospedadores (tanto en plantas silvestres como cultivadas), (Sridhar y Raviraja, 1995). El grupo fúngico más interesante es el que corresponde a los micelios estériles, éstos se aislaron en las dos plantas medicinales investigadas. El aislamiento de micelios estériles, es quizás uno de los resultados más interesantes de la presente investigación micológica, que necesita ser producto de investigación, la tasa de infestación es del $48,33 \%$. un porcentaje del $33,33 \%$ corresponde a hongos que corresponden a micelios estériles, se considera un porcentaje elevado de acuerdo a la tasa de infestación, el 18,33\% corresponde a muestras no infestadas con hongos.

3.I.2 Tasa de infestación "ñachag" Bidens andicola Kunth Se identifican 5 géneros de hongos diferentes: Alternaria spp; Cladosporium spp.; Coelomycetes, Fusarium spp; Nigrospora Sp. La tasa de infestación más alta se da con el género Fusarium con un porcentaje del 24,49\%; el género Nigrospora se encuentra en un porcentje del 16,33\%; hongos con micelios estériles, corresponde el $40,33 \%$ mientras, que la muestras no infestadas corresponde $50,41 \%$.

Se muestran fotos al microscopio de hongos endófitos y fitopatógenos de cada uno de los géneros
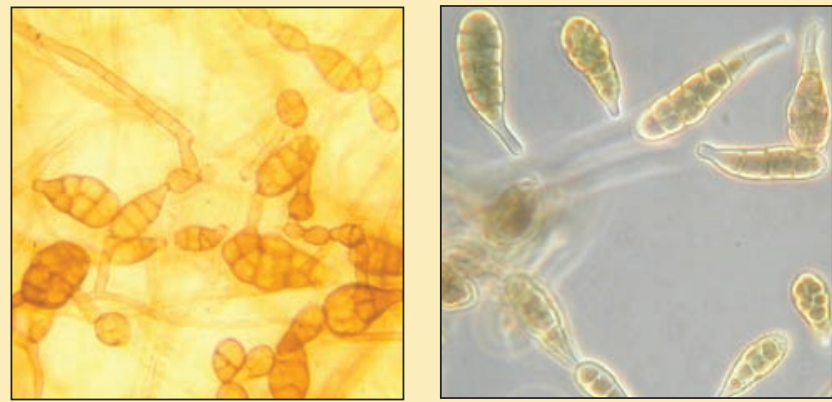

Figuras I y 2. Hongos endófitos en el género Alternaria Sp. Fuente: Ernesto Delgado.
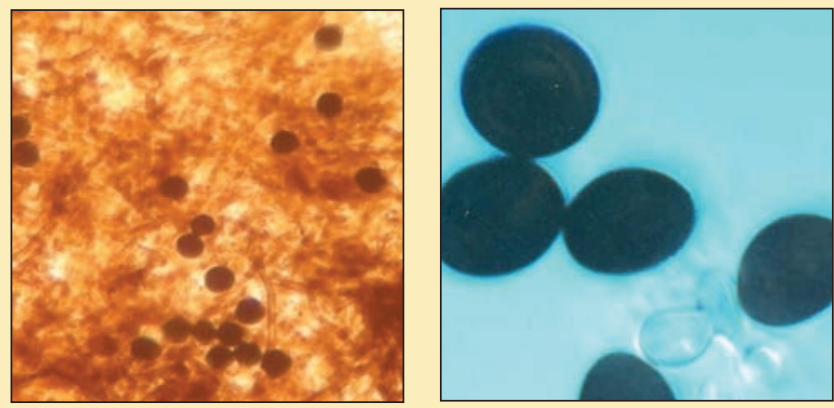

Figuras 3 y 4 . Hongos endófitos en el género Nigrospora Sp. Fuente: Ernesto Delgado.
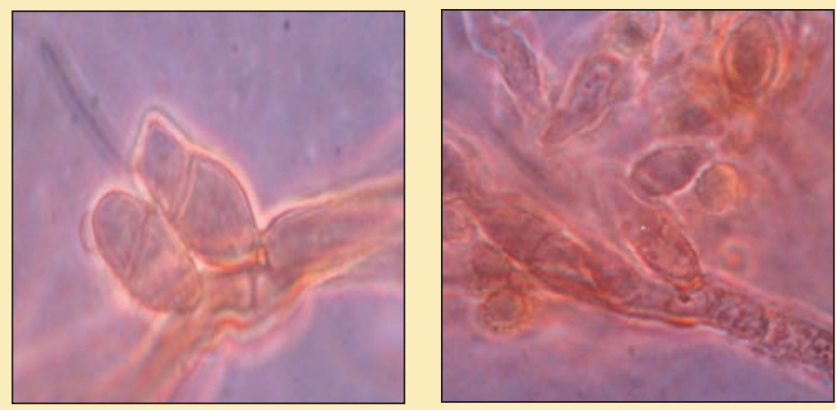

Figuras 5 y 6. Hongos endófitos en el género Cladosporium Sp. Fuente: Ernesto Delgado. 

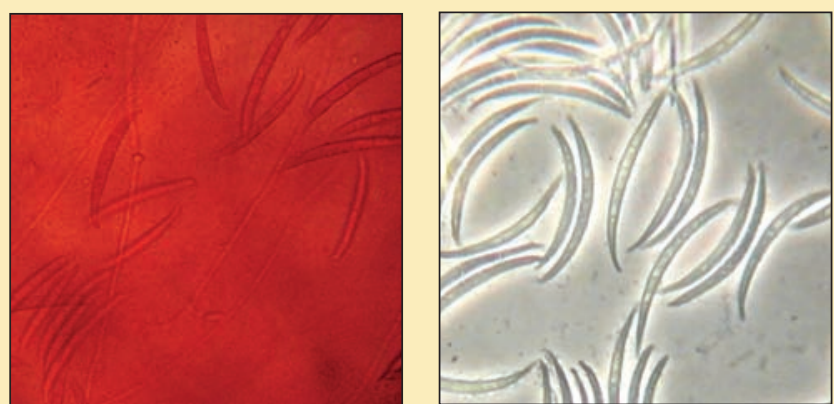

Figuras 7 y 8 . Hongos endófitos en el género Fusarium Sp. Fuente: Ernesto Delgado.

3.2. Hongos fitopatógenos aislados y clasificados taxonómicamente

\subsection{Fitopatología I.}

Botrytis cinerea (Figuras 9 y 10). Agente causal de la podredumbre gris (Rosa Sp.)
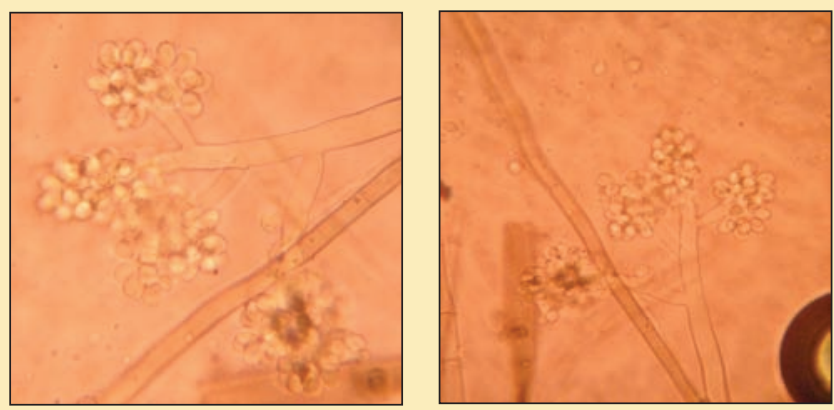

Figuras 9 y 10. Estructura del hongo Botrytis cinerea al microscopio. Fuente: Ernesto Delgado.

\subsubsection{Fitopatología II.}

Antracnosis (Figuras II y I2) (Colletotrichum gloesporoides) en tomate de árbol Cyphomandra betacea (Cav) Sendt. Solanaceae.
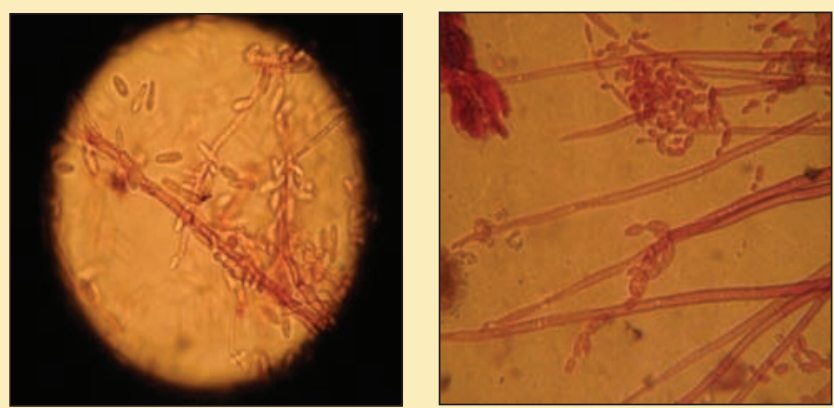

Figuras II y I2. Estructura del hongo Colletotrichum gloesporoides al microscopio. Fuente: Ernesto Delgado.

\subsubsection{Fitopatología III.}

Mildiu de la vid (Figuras I3 y I4) (Plasmopara viticola).
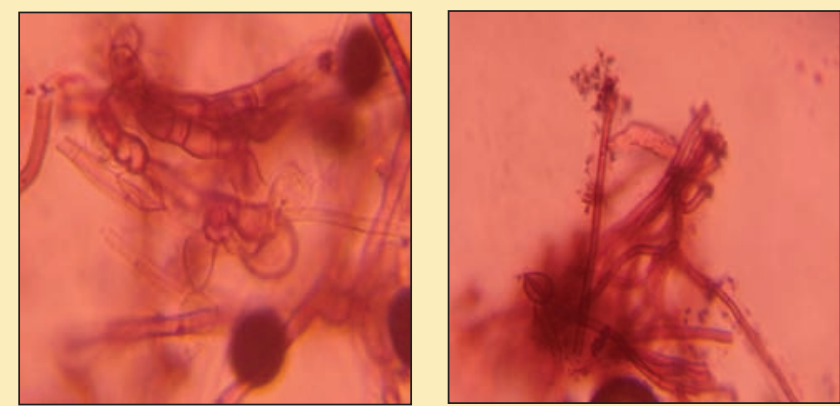

Figuras 13 y 14. Estructura del hongo Plasmopara viticola al microscopio. Fuente: Ernesto Delgado.

\subsubsection{Fitopatología IV.}

Pythium (Pythium. Sp) El Pythium llamado tizón o mancha de grasa, El género Pythium genera, pudriciones de semilla y raíces, Se aisló el hongo del clavel (Dianthus caryophyllus)
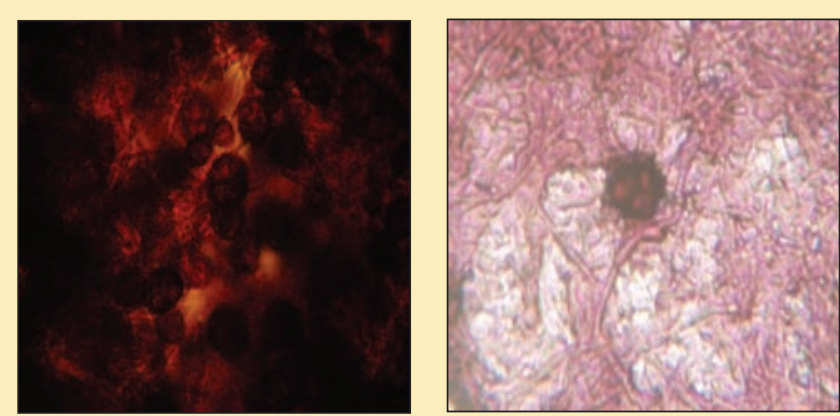

Figuras 15 y 16 . Estructura del hongo (Pythium. Sp) al microscopio. Fuente: Ernesto Delgado.

\subsubsection{Fitopatología V}

Taphrina deformans
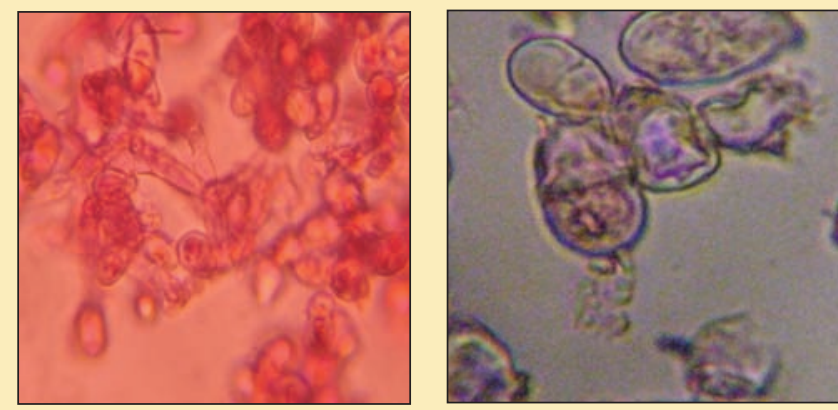

Figuras 17 y 18. Estructura del hongo Taphrina deformans al microscopio. Fuente: Ernesto Delgado. 


\section{Delgado, Vásquez e Icaza}

\subsubsection{Fitopatología VI.}

Fumago Sp negrilla en cacao- especies de hongos que forman una película negra, en hojas y partes de la planta. El agente causal de la negrilla en cacao es un hongo imperfecto.
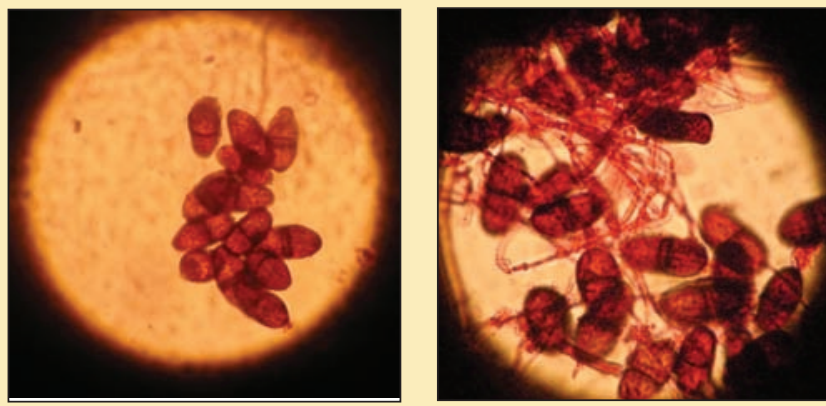

Figuras 19 y 20. Estructura del hongo Fumago Sp. al microscopio. Fuente: Ernesto Delgado.

\subsubsection{Fitopatología VII.}

Guignardia citricarpa Kielly mancha tardía en "Citrus cinensis" (naranja).

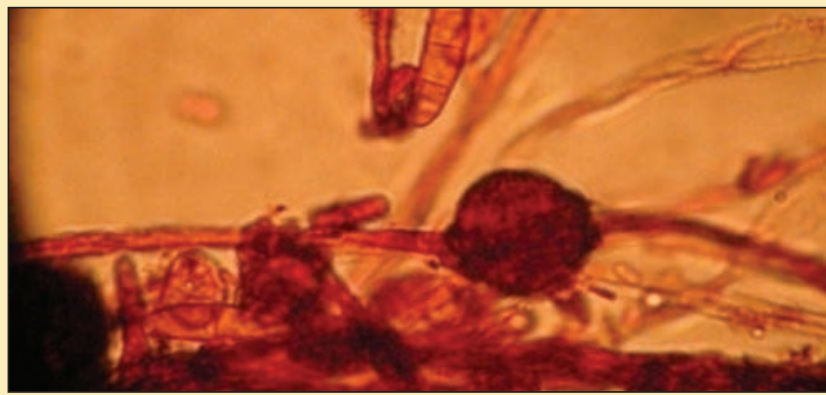

Figura 2I. Estructura del hongo Guignardia citricarpa Kielly al microscopio. Fuente: Ernesto Delgado.

\subsubsection{Fitopatología VIII.}

Género Pestalotia Sp. es la especie causante del marchitamiento y muerte de hojas y ramas jóvenes, se reconoce la presencia de más de 200 especies de este género, es común su presencia en plantas de banano.
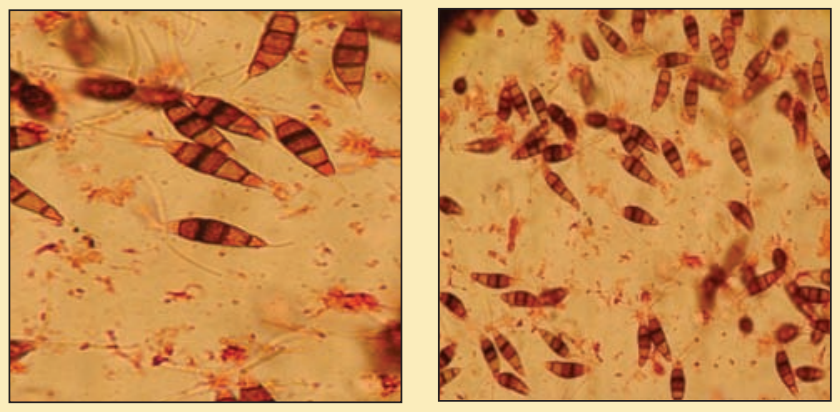

Figuras 22 y 23 Estructura del hongo Pestalotia Sp.al microscopio. Fuente: Ernesto Delgado.

\subsubsection{Fitopatología IX.}

Moniliasis, Monilia roreri (Figuras 24 y 25) también conocida como Pudrición acuosa, Helada, Mancha, Ceniza o Enfermedad de Quevedo, está causada por el hongo Monilia (Moniliophthora) roreri E. (C.y P.)
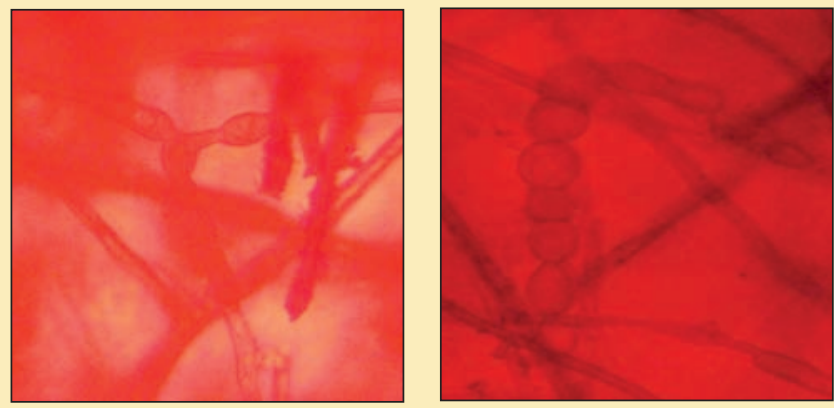

Figuras 24 y 25. Estructura del hongo Monilia, Moniliophthora roreri E. (C.y P.) al microscopio. Fuente: Ernesto Delgado.

\subsection{Fitopatología $X$.}

Ceratocystis fimbriata Enfermedad del machete (Figuras 26 y 27).
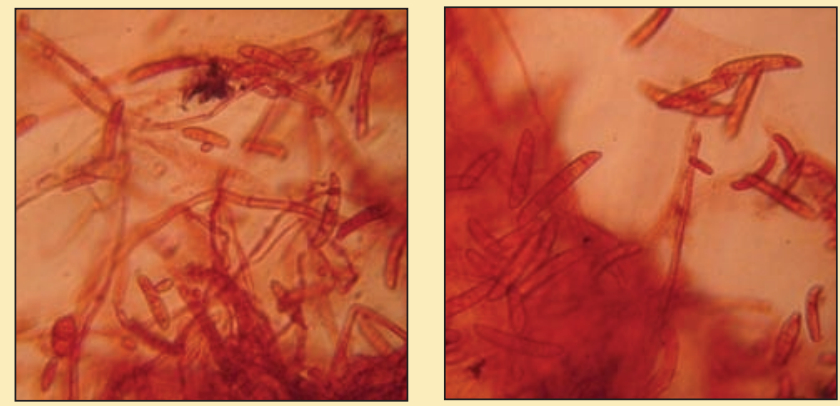

Figuras 26 y 27. Estructura del hongo Ceratocystis fimbriata al microscopio. Fuente: Ernesto Delgado.

\subsection{I Fitopatología XI.}

Bremia lactucae (Figuras 28 y 29).
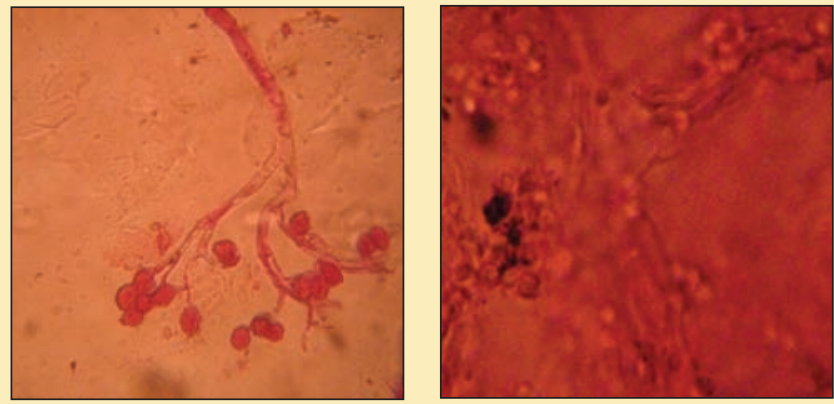

Figuras 28 y 29. Estructura del hongo Bremia lactucae al microscopio. Fuente: Ernesto Delgado. 
Tabla 2. Porcentaje de inhibición del Colletotrichum gloesporoides. En este caso el porcentaje más alto de inhibición se da con los hongos endófitos A7 con el 73,9\% y Ax con el $89,1 \%$.

\section{PORCENTAJE DE INHIBICIÓN Colletotrichum gloesporoides}

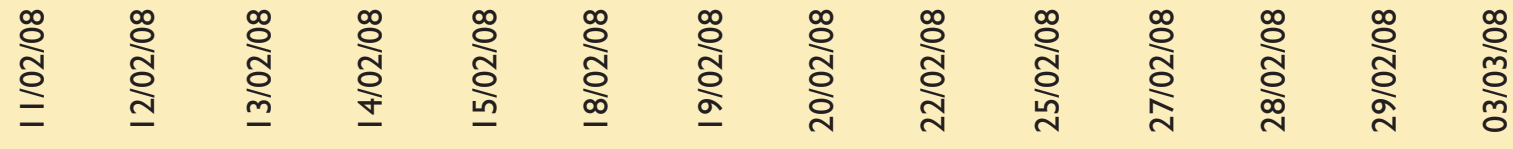

\begin{tabular}{lllllllllllllll}
\hline AI & 0,0 & 0,0 & 0,0 & 5,9 & 0,0 & 29,2 & 34,6 & 34,6 & 40,7 & 40,7 & 35,7 & 44,4 & 42,9 & 67,4 \\
A2 & 14,3 & 0,0 & 0,0 & 5,9 & $-6,2$ & 25,0 & 30,8 & 30,8 & 37,0 & 37,0 & 35,7 & 37,0 & 35,7 & 60,9 \\
A3 & 14,3 & 20,0 & 15,4 & 29,4 & 25,0 & 45,8 & 50,0 & 50,0 & 51,9 & 51,9 & 53,6 & 51,9 & 53,6 & 71,7 \\
A4 & 0,0 & 20,0 & 0,0 & 17,6 & 12,5 & 37,5 & 42,3 & 46,2 & $48, I$ & $48, I$ & 50,0 & 55,6 & 53,6 & 67,4 \\
A5 & 14,3 & 0,0 & 7,7 & 11,8 & 6,3 & 29,2 & 34,6 & 34,6 & 37,0 & 37,0 & 39,3 & 37,0 & 35,7 & 63,0 \\
A6 & $-14,3$ & $-20,0$ & $-30,8$ & $-5,9$ & $-25,0$ & 16,7 & $23, I$ & $23, I$ & 25,9 & 25,9 & 28,6 & 25,9 & 28,6 & 56,5 \\
A7 & $\mathbf{2 8 , 6}$ & $\mathbf{5 0 , 0}$ & $\mathbf{5 3 , 8}$ & $\mathbf{5 8 , 8}$ & $\mathbf{3 7 , 5}$ & $\mathbf{6 2 , 5}$ & $\mathbf{5 3 , 8}$ & $\mathbf{5 7 , 7}$ & $\mathbf{5 9 , 3}$ & $\mathbf{5 5 , 6}$ & $\mathbf{5 7 , I}$ & $\mathbf{5 5 , 6}$ & $\mathbf{5 7 , 1}$ & $\mathbf{7 3 , 9}$ \\
A8 & $\mathbf{0 , 0}$ & 0,0 & $\mathbf{0 , 0}$ & $\mathbf{5 , 9}$ & $\mathbf{6 , 3}$ & $\mathbf{3 3 , 3}$ & $\mathbf{3 8 , 5}$ & $\mathbf{4 2 , 3}$ & $\mathbf{4 4 , 4}$ & $\mathbf{4 0 , 7}$ & $\mathbf{4 2 , 9}$ & $\mathbf{4 4 , 4}$ & $\mathbf{4 6 , 4}$ & $\mathbf{6 5 , 2}$ \\
Ax & $\mathbf{2 8 , 6}$ & $\mathbf{5 0 , 0}$ & $\mathbf{6 1 , 5}$ & $\mathbf{7 0 , 6}$ & $\mathbf{6 8 , 8}$ & $\mathbf{7 9 , 2}$ & $\mathbf{8 4 , 6}$ & $\mathbf{8 4 , 6}$ & $\mathbf{8 1 , 5}$ & $\mathbf{8 I , 5}$ & $\mathbf{8 2 , I}$ & $\mathbf{8 1 , 5}$ & $\mathbf{8 2 , I}$ & $\mathbf{8 9 , 1}$ \\
\hline
\end{tabular}

Tabla 3. Radio dirigido hacia el centro de la caja hongo endófito-hongo Botrytis cinerea.

\begin{tabular}{|c|c|c|c|c|c|}
\hline \multicolumn{6}{|c|}{ FITOPATOLOGÍA: Botrytis cinerea } \\
\hline \multicolumn{6}{|c|}{ Análisis: 28 de febrero de 2008} \\
\hline & 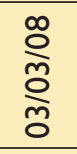 & $\begin{array}{l}\stackrel{\infty}{0} \\
\text { ô } \\
\text { ᄋे }\end{array}$ & 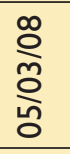 & $\begin{array}{l}\stackrel{\infty}{0} \\
\text { O̊ } \\
\stackrel{0}{\circ}\end{array}$ & $\begin{array}{l}\stackrel{\infty}{\rho} \\
\stackrel{\rho}{0} \\
\infty \\
\end{array}$ \\
\hline $\mathbf{R}$ & 4,6 & 5,0 & 5,5 & 5,7 & 5,7 \\
\hline Al & 2,3 & 2,3 & 2,3 & 2,3 & 2,0 \\
\hline A2 & 2,5 & 2,5 & 2,5 & 2,5 & 2,3 \\
\hline $\mathbf{A 3}$ & 2,2 & 2,3 & 2,4 & 2,4 & 2,2 \\
\hline A4 & 2,0 & 2,0 & 2,0 & 2,0 & 2,1 \\
\hline A5 & 2,0 & 2,0 & 2,0 & 2,0 & 2,0 \\
\hline A6 & 2,3 & 2,3 & 2,5 & 2 & 2,4 \\
\hline A7 & 2,7 & 2,7 & 2,6 & 2,6 & 2,2 \\
\hline A8 & 2,6 & 2,6 & 2,6 & 2,6 & 2,0 \\
\hline A9 & 2,5 & 2,8 & 2,8 & 2,8 & 2,5 \\
\hline A 10 & 2,0 & 2,1 & 2,2 & 2,2 & 2,0 \\
\hline$A \mid 2$ & 2,4 & 2,6 & 2,6 & 2,6 & 2,5 \\
\hline 13 & 1,9 & I,5 & I,5 & 1,8 & I,7 \\
\hline Al4 & 2,0 & 2,0 & 1,9 & 1,9 & 2,0 \\
\hline$A X$ & 2,1 & 2,0 & 1,8 & 1,8 & 2,0 \\
\hline
\end{tabular}


Tabla 4. Porcentaje de inhibición hongo endófito-hongo Botrytis cinerea, el mayor porcentaje se da con el endófito Al 3 con un $70,2 \%$.

\begin{tabular}{cccccc}
\hline PORCENTAJE DE INHIBICIÓN Botrytis cinerea & & & \\
\hline A1 & $\mathbf{5 0 , 0}$ & $\mathbf{5 4 , 0}$ & $\mathbf{5 8 , 2}$ & $\mathbf{5 9 , 6}$ & $\mathbf{6 4 , 9}$ \\
A2 & 45,7 & 50,0 & 54,5 & 56,1 & 59,6 \\
A3 & 52,2 & 54,0 & 56,4 & 57,9 & 61,4 \\
A4 & 56,5 & 60,0 & 63,6 & 64,9 & 63,2 \\
A5 & 56,5 & 60,0 & 63,6 & 64,9 & 64,9 \\
A6 & 50,0 & 54,0 & 54,5 & 56,1 & 57,9 \\
A7 & 41,3 & 46,0 & 52,7 & 54,4 & 61,4 \\
A8 & 43,5 & 48,0 & 52,7 & 54,4 & 64,9 \\
A9 & 45,7 & 44,0 & 49,1 & 50,9 & 56,1 \\
A10 & 56,5 & 58,0 & 60,0 & 61,4 & 64,9 \\
A12 & 47,8 & 48,0 & 52,7 & 54,4 & 56,1 \\
A13 & 58,7 & 70,0 & 72,7 & 68,4 & 70,2 \\
A14 & 56,5 & 60,0 & 65,5 & 66,7 & 64,9 \\
AX & 54,3 & 60,0 & 67,3 & 68,4 & 64,9 \\
\hline
\end{tabular}

\subsubsection{Cultivos Duales Hongo Endófito Plasmophora viti-} cola

Se presenta el cultivo (Figura 32), la medición en centímetros de los radios, en los cultivos duales, a partir del I4 de febrero de 2008, (Tabla 5) A= Hongo endófito; $R=$ Caja de control. Se incluyen asimismo los porcentajes de inhibición (Tabla 6). En este caso el porcentaje más alto de inhibición se da con los hongos endófitos A 10 con el $82,89 \%$ y AI 2 con el $82,8 \%$.

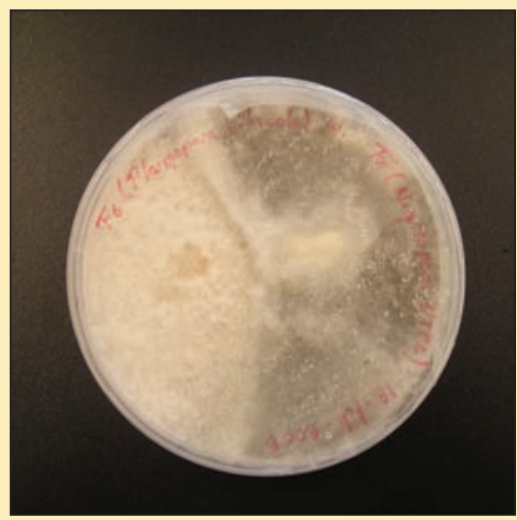

Figura 32. Foto cultivo dual hongo endófito Plasmophora viticola. Fuente: Ernesto Delgado.

\subsubsection{Hongo Endófito Pythium spp.}

El cultivo de este hogo se presenta (Figura 33 ) incluyendo la evolución de radios de los cultivos (Tabla 7) y los porcentajes de inhibición (Tabla 8).

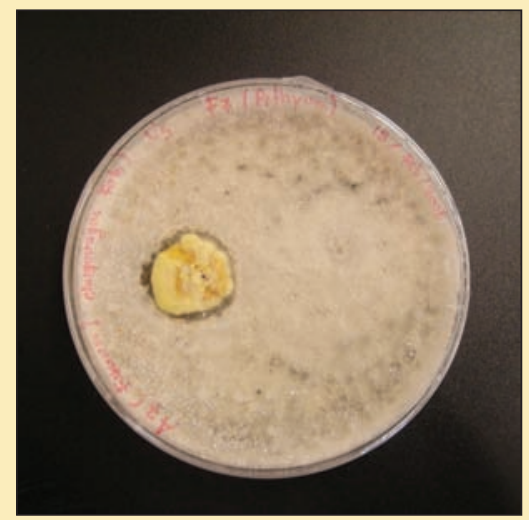

Figura 33. Foto cultivo dual hongo endófito - Pythium spp. Análisis 18 de febrero de 2008. 
38 Delgado, Vásquez e Icaza

Tabla 5. Radios de los cultivos de la Plasmopara viticola.

\begin{tabular}{|c|c|c|c|c|c|c|c|c|}
\hline & \multicolumn{8}{|c|}{ FITOPATOLOGÍA: Plasmopara viticola } \\
\hline & \multicolumn{8}{|c|}{ FECHA. I 4 de febrero de 2008} \\
\hline & $18 / 02 / 2008$ & 19/02/2008 & $20 / 02 / 2008$ & $22 / 02 / 2008$ & $25 / 02 / 2008$ & $27 / 02 / 2008$ & $28 / 02 / 2008$ & $29 / 02 / 2008$ \\
\hline Al & 4,3 & 5,8 & 5,8 & 5,8 & 5,8 & 5,8 & 5,8 & 5,8 \\
\hline $\mathrm{A} 2$ & 2,2 & 2,1 & 2,0 & 2,0 & 2,0 & 2,0 & 2,2 & 2,0 \\
\hline A3 & 2,1 & 2,1 & 2,0 & 2,0 & 2,0 & 2,1 & 2,7 & 2,1 \\
\hline A4 & 1,2 & 1,6 & 1,6 & 1,9 & 2,0 & 2,2 & 2,2 & 2,0 \\
\hline A5 & 2,0 & 2,0 & 1,8 & 1,9 & 1,7 & 1,8 & I,5 & 2,0 \\
\hline A6 & 2,3 & 2,3 & 2,2 & 2,2 & 2,2 & 2,2 & 2,1 & 2,0 \\
\hline A7 & 2,0 & 1,9 & I,8 & I,8 & 1,9 & 2,0 & $\mathrm{I}, 0$ & 2,5 \\
\hline A8 & $\mathrm{I}, 5$ & I,5 & I,5 & I,5 & I,5 & I,5 & I,5 & I,5 \\
\hline A9 & 2,2 & 2,2 & 2,3 & $\mathrm{I}, 7$ & $\mathrm{I}, 8$ & 1,9 & 2,0 & I,8 \\
\hline AlO & 2,0 & 1,8 & $\mathrm{I}, 7$ & 1,3 & $\mathrm{I}, 2$ & $\mathrm{I}, 3$ & I,5 & $\mathrm{I}, 2$ \\
\hline All & 2,0 & 2,0 & 2,0 & $\mathrm{I}, 3$ & $\mathrm{I}, \mathrm{I}$ & 1,0 & 2,0 & 1,0 \\
\hline $\mathrm{A} 12$ & 2,5 & 2,5 & 2,3 & $\mathrm{I}, 2$ & $\mathrm{I}, \mathrm{I}$ & $\mathrm{I}, 0$ & 1,0 & $\mathrm{I}, 0$ \\
\hline $\mathrm{A} \mid 3$ & I,5 & I,5 & I,7 & I,5 & 1,2 & 1,2 & I,5 & $\mathrm{I}, 4$ \\
\hline Al4 & 2,0 & 2,3 & I,8 & 2,0 & 2,0 & 2,0 & 2,1 & 2,0 \\
\hline$A X$ & 1,8 & 1,8 & 1,9 & I,8 & 1,8 & I,8 & 1,8 & 1,8 \\
\hline
\end{tabular}

Tabla 6. Porcentajes de inhibición Plasmopara viticola.

\begin{tabular}{|c|c|c|c|c|c|c|c|c|}
\hline \multicolumn{9}{|c|}{ PORCENTAJE DE INHIBICIÓN: Plasmopara viticola } \\
\hline Al & 48,8 & 63,8 & 65,5 & 65,5 & 65,5 & 65,5 & 62,1 & 65,5 \\
\hline A2 & 51,2 & 63,8 & 65,5 & 65,5 & 65,5 & 63,8 & 53,4 & 63,8 \\
\hline $\mathbf{A} 3$ & 72,1 & 72,4 & 72,4 & 67,2 & 65,5 & 62,1 & 62,1 & 65,5 \\
\hline A4 & 53,5 & 65,5 & 69,0 & 67,2 & 70,7 & 69,0 & $74, I$ & 65,5 \\
\hline A5 & 46,5 & 60,3 & 62,1 & 62,1 & 62,1 & 62,1 & 63,8 & 65,5 \\
\hline A6 & 53,5 & 67,2 & 69,0 & 69,0 & 67,2 & 65,5 & 82,8 & 56,9 \\
\hline A7 & 65,1 & 74,1 & 74,1 & 74,1 & 74,1 & 74,1 & 74,1 & 74,1 \\
\hline A8 & 48,8 & 62,1 & 60,3 & 70,7 & 69,0 & 67,2 & 65,5 & 69,0 \\
\hline A9 & 53,5 & 69,0 & 70,7 & 77,6 & 79,3 & 77,6 & $74, I$ & 79,3 \\
\hline Alo & 53,5 & 65,5 & 65,5 & 77,6 & 81,0 & 82,8 & 65,5 & 82,8 \\
\hline$A \mid 2$ & 41,9 & 56,9 & 60,3 & 79,3 & $8 I, 0$ & 82,8 & 82,8 & 82,8 \\
\hline$A \mid 3$ & 65,1 & $74, I$ & 70,7 & $74, I$ & 79,3 & 79,3 & 74,1 & 75,9 \\
\hline Al4 & 53,5 & 60,3 & 69,0 & 65,5 & 65,5 & 65,5 & 63,8 & 65,5 \\
\hline$A x$ & 58,1 & 69,0 & 67,2 & 69,0 & 69,0 & 69,0 & 69,0 & 69,0 \\
\hline
\end{tabular}


Tabla 7. Medición en centímetros de los radios, en los cultivos duales a partir del 14 de febrero de 2008, A= Hongo endófito; $\mathrm{R}=$ Caja de control

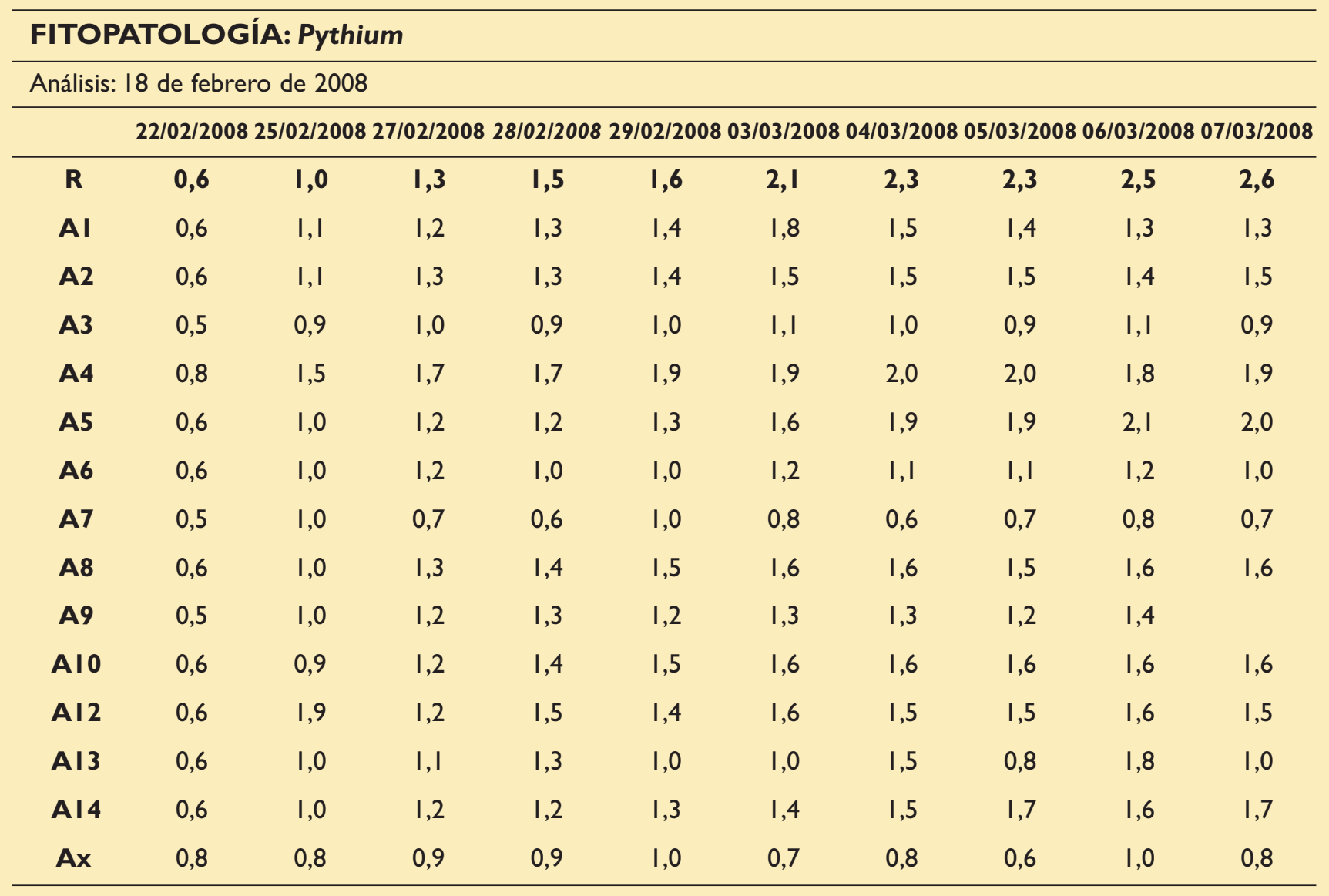

Tabla 8. Porcentajes de inhibición en Pythium. En este caso el porcentaje más alto de inhibición se da con los hongos endófitos $\mathrm{A} 7$ con el $73, \mathrm{I} \%$ y FX con el $69,2 \%$

\begin{tabular}{|c|c|c|c|c|c|c|c|c|c|c|}
\hline \multicolumn{11}{|c|}{ PORCENTAJE DE INHIBICIÓN: Phytium } \\
\hline Al & 0,0 & $-10,0$ & 7,7 & 13,3 & 12,5 & 14,3 & 34,8 & 39,1 & 48,0 & 50,0 \\
\hline A2 & 0,0 & $-10,0$ & 0,0 & 13,3 & 12,5 & 28,6 & 34,8 & 34,8 & 44,0 & 42,3 \\
\hline A3 & 16,7 & 10,0 & 23,1 & 40,0 & 37,5 & 47,6 & 56,5 & 60,9 & 56,0 & 65,4 \\
\hline A4 & $-33,3$ & $-50,0$ & $-30,8$ & $-13,3$ & $-18,8$ & 9,5 & 13,0 & 13,0 & 28,0 & 26,9 \\
\hline A5 & 0,0 & 0,0 & 7,7 & 20,0 & 18,8 & 23,8 & 17,4 & 17,4 & 16,0 & 23,1 \\
\hline A6 & 0,0 & 0,0 & 7,7 & 33,3 & 37,5 & 42,9 & 52,2 & 52,2 & 52,0 & 61,5 \\
\hline A7 & 16,7 & 0,0 & 46,2 & 60,0 & 37,5 & 61,9 & 73,9 & 69,6 & 68,0 & 73,1 \\
\hline A8 & 0,0 & 0,0 & 0,0 & 6,7 & 6,3 & 23,8 & 30,4 & 34,8 & 36,0 & 38,5 \\
\hline A9 & 16,7 & 0,0 & 7,7 & 13,3 & 25,0 & 38,1 & 43,5 & 47,8 & 44,0 & \\
\hline Alo & 0,0 & 10,0 & 7,7 & 6,7 & 6,3 & 23,8 & 30,4 & 30,4 & 36,0 & 38,5 \\
\hline A 12 & 0,0 & $-90,0$ & 7,7 & 0,0 & 12,5 & 23,8 & 34,8 & 34,8 & 36,0 & 42,3 \\
\hline$A \mid 3$ & 0,0 & 0,0 & 15,4 & 13,3 & 37,5 & 52,4 & 34,8 & 65,2 & 28,0 & 61,5 \\
\hline Al4 & 0,0 & 0,0 & 7,7 & 20,0 & 18,8 & 33,3 & 34,8 & 26,1 & 36,0 & 34,6 \\
\hline Fx & $-33,3$ & 20,0 & 30,8 & 40,0 & 37,5 & 66,7 & 65,2 & 73,9 & 60,0 & 69,2 \\
\hline
\end{tabular}


3.4.5 Hongo Endófito Monilia roreri

El cultivo de este hongo se presenta en la Figura 35, como en casos anteriores se incluye la evolución de radios de los cultivos (Tabla 9) y los porcentajes de inhibición (Tabla 10).
Figura 35. Foto del hongo endófito, Monilia roreri. Fuente: Ernesto Delgado.

Tabla 9 Medición en centímetros de los radios, en los cultivos duales a partir del 9 de febrero de 2008, A= Hongo endófito; $\mathrm{R}=$ Caja de control

\begin{tabular}{|c|c|c|c|c|c|c|}
\hline \multicolumn{7}{|c|}{ FITOPALOTOGÍA: Monilia roreri } \\
\hline \multicolumn{7}{|c|}{ ANÁLISIS: 9 Febrero 2008} \\
\hline & 05/03/08 & 06/03/08 & 07/03/08 & $11 / 03 / 08$ & $12 / 03 / 08$ & $18 / 03 / 08$ \\
\hline $\mathbf{R}$ & 0,4 & $\mathbf{I}, \mathrm{I}$ & 1,6 & 3,8 & 4,5 & 5,7 \\
\hline Al & 0,6 & 0,7 & 0,6 & 0,6 & 0,6 & 1,3 \\
\hline A2 & 0,8 & 0,5 & 0,6 & 0,7 & 0,8 & 2,4 \\
\hline A3 & 0,9 & 1,5 & & 2,3 & 2,5 & 2,3 \\
\hline A4 & 0,7 & $\mathrm{I}, \mathrm{I}$ & ।,4 & $\mathrm{I}, 6$ & $\mathrm{I}, 8$ & $\mathrm{I}, 8$ \\
\hline A6 & 0,8 & 1,2 & 1,6 & 1,6 & 1,6 & 1,6 \\
\hline A7 & 0,6 & $\mathrm{I}, \mathrm{I}$ & 1,3 & & & 2,0 \\
\hline A9 & I,I & 1,6 & 1,9 & 2,2 & 2,1 & 2,1 \\
\hline Alo & 0,6 & 0,9 & 1,0 & & & \\
\hline$A \mid 2$ & 0,9 & I,6 & ।,7 & 2,5 & 2,5 & 2,5 \\
\hline$A \mid 3$ & $\mathrm{I}, \mathrm{I}$ & I,5 & I,5 & ।,7 & ।,7 & 2,0 \\
\hline$F x$ & 0,6 & ।,2 & 1,2 & ।,5 & ।,8 & 1,5 \\
\hline
\end{tabular}

Tabla 10. Porcentajes de inhibición de la Monilia roreri. En este caso el porcentaje más alto de inhibición se da con el hongo endófito A7 con el 69,0\%

\begin{tabular}{ccccc}
\hline PORCENTAJE DE INHIBICIÓN Monilia roreri & & \\
\hline A1 & 6,3 & 26,7 & 63,6 & 62,1 \\
A2 & 0,0 & 40,0 & 54,5 & $\mathbf{6 7 , 2}$ \\
A3 & $-6,2$ & 23,3 & 58,2 & 60,3 \\
A4 & $-12,5$ & 33,3 & 60,0 & 60,3 \\
A5 & 0,0 & 16,7 & 54,5 & 55,2 \\
A6 & $-6,2$ & 43,3 & 54,5 & 56,9 \\
A7 & $-12,5$ & $\mathbf{5 0 , 0}$ & $\mathbf{6 7 , 3}$ & $\mathbf{6 9 , 0}$ \\
A8 & 12,5 & 33,3 & 60,0 & 60,3 \\
Ax & 6,3 & 33,3 & 60,0 & $\mathbf{6 2 , 1}$ \\
\hline
\end{tabular}


3.5 Pruebas de Interacción entre Hongos y Bacterias Los resultados de la interacción antagónica de algunas de las cepas de hongos aislados frente a bacterias fitopatógenas, se presentan a continuación (Figuras 36 y 37$)$

\subsection{Valoración in vitro de la actividad de antagonismo} hongo endófito-bacteria Erwinia Caratovora.

Los resultados se representan como (-) no hay antagonismo y $(+)$ se reporta antagonismo, de parte de los hongos endófitos (Tabla I I). Nótese el antagonismo en los endófitos AI3, A7 y A5.
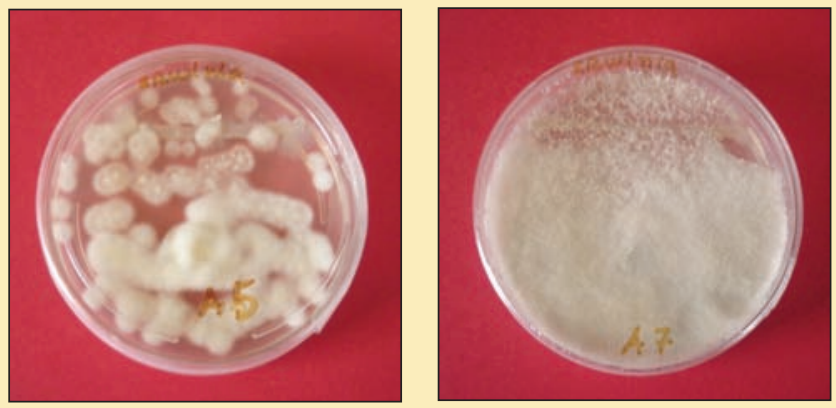

Figura 36. Fotos de la Erwinia Caratovora. Fuente: Ernesto Delgado.

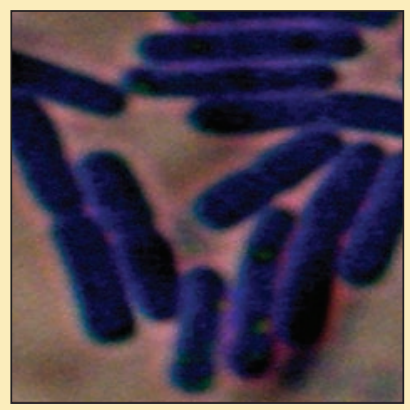

Figura 37. Foto al microscopio “Erwinia caratovora". Fuente: Ernesto Delgado.

Tabla I I.Valoración in vitro de la actividad de antagonismo de los hongos endófitos con la bacteria Erwinia caratovora.

\begin{tabular}{lc} 
& BACTERIA: Erwinia caratovora \\
\hline Endófito A4 & - \\
Endófito AI3 & + \\
Endófito AX & - \\
Endófito $A 7$ & + \\
Endófito $A 5$ & + \\
Endófito $A 2$ & - \\
Endófito $A I$ & - \\
\hline
\end{tabular}

3.5.2 Valoración in vitro de la actividad de antagonismo hongo endófito-bacteria Agrobacterium

Igualmente, la interacción antagónica del hongo endófito-bacteria Agrobacterium se presenta en las Figuras 38 y 39, y las valoraciones en la Tabla 12.
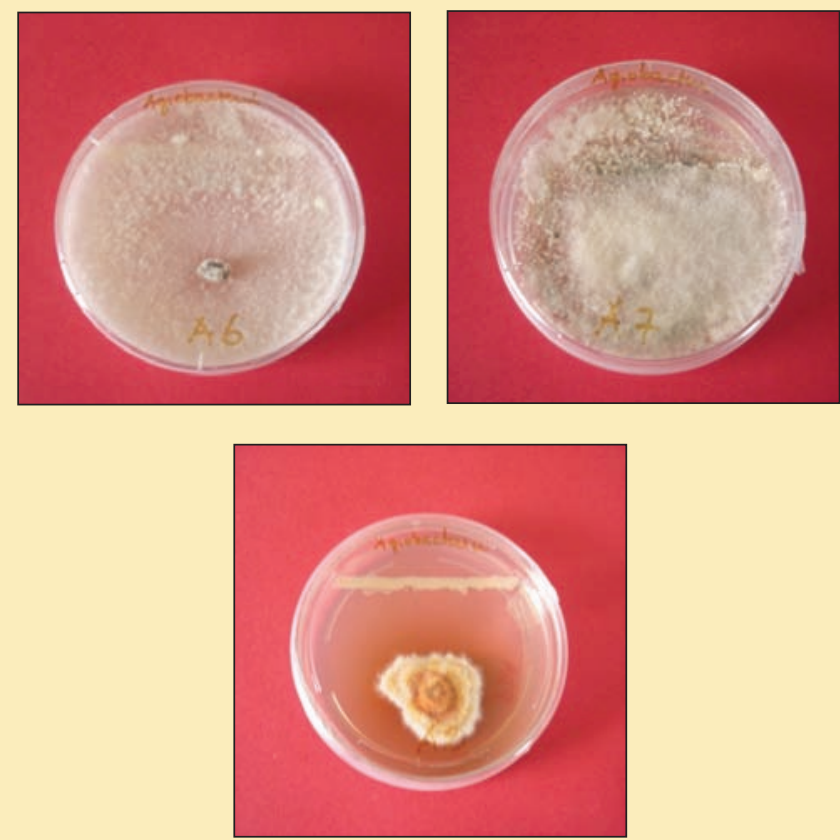

Figuras 38. Agrobacterium Sp. in vitro. Fuente: Ernesto Delgado.

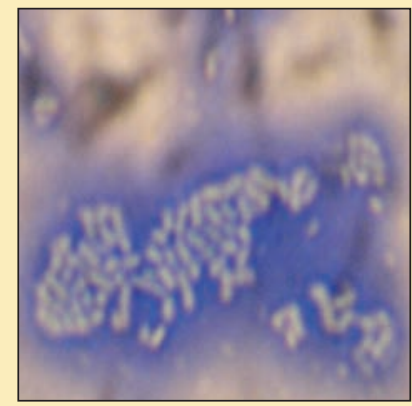

Figura 39. Foto al microscopio del "Agrobacterium tumefasiens”. Fuente: Ernesto Delgado.

Tabla 12. Valoración in vitro del Agrobacterium.

\begin{tabular}{lc}
\hline & BACTERIA:Agrobacterium \\
\hline Endófito $A 4$ & - \\
Endófito $A / 3$ & + \\
Endófito AX & + \\
Endófito $A$ I & - \\
Endófito $A 2$ & - \\
Endófito $A 5$ & + \\
Endófito $A 6$ & + \\
Endófito $A 7$ & +
\end{tabular}




\section{2 \\ Delgado, Vásquez e Icaza}

3.5.3 Valoración in vitro de la actividad de antagonismo hongo endófito-bacteria Xanthomonas.

Se presenta en la Tabla 13 el antagonismo registrado en los endófitos $A 2, A 5$ y $A 6$.

Tabla 13. Valoración in vitro del hongo endófito con la bacteria Xanthomonas.

\begin{tabular}{lc}
\hline & BACTERIA: Xanthomonas \\
\hline Endófito A4 & - \\
Endófito AI3 & - \\
Endófito AX & - \\
Endófito A2 & + \\
Endófito A5 & + \\
Endófito A6 & + \\
\hline
\end{tabular}

\section{Conclusiones}

Los taxa fúngicos más frecuentes fueron: Alternaria, Fusarium, Nigrospora, Phoma, Coelomycetes, el mayor porcentaje de infestación correspondió a los denominados «Mycelia sterilia» (micelios estériles) siendo de particular interés su actividad antagonista.

Esta investigación sobre la presencia de endófitos fúngicos en las plantas (Chuquiragua jussieui) $Y$ ñachag (Bidens andicola Kunth) consideradas medicinales en la farmacopea homeopática nacional, demostró que varias especies de hongos $y$, especialmente, los micelios estériles aislados, podrían constituir un óptimo y quizás inocuo material biológico para investigaciones futuras, en particular por la marcada actividad antagónica con hongos y bacterias fitopatógenas. Considerando como perspectivas futuras el uso de estos microorganismos para la elaboración y formulación de productos para el control biológico de enfermedades fitopatógenas, causadas por hongos y bacterias. El porcentaje más elevado de antagonismo se da con el hongo AX (micelios estériles) con un porcentaje del $89,1 \%$ frente a Colletotrichum gloesporoides agente causal de la antracnosis en el tomate de árbol (Cyphomandra betaceae) (Cav) Sendt Solanaceae. En cuanto a bacterias fitopatógenas, se consideran los cuatro géneros Agrobacterium Sp.; Erwinia Sp; Pseudomonas Sp.; $y$ Xanthomonas Sp. Agentes causales de mayor incidencia, en vegetales, los resultados de igual manera son muy satisfactorios, según lo encontrado.
3.5.4 Valoración in vitro de la actividad de antagonismo hongo endófito-bacteria Pseudomonas.

Nótese el gran antagonismo registrado contra esta bacteria en todos los endófitos estudiados, excepto en el endófito A4 (Tabla 14).

Tabla 14. Valoración in vitro del hongo endófito con la bacteria Pseudomonas.

\begin{tabular}{cc}
\hline & BACTERIA: Pseudomonas \\
\hline Endófito A4 & - \\
Endófito $A 13$ & + \\
Endófito $A X$ & + \\
Endófito $A 7$ & + \\
\hline
\end{tabular}

\section{Agradecimiento:}

A las Dras. Marinella Rodolfi y Solveig Tossi Senior Research Scientist Sezione di Micologia Dipartimento di Ecologia del Territorio Università di Pavia Italia por la predisposición y asesoramiento, en la presente investigación. A mis estudiantes de la cátedra de Biotecnología, por el apoyo y respaldo en la presente investigación.

\section{Referencias}

Ainsworth, G.C. 197I. Dictionary of the fungi. VI ed. Commonwealth Mycological Institute, Kew, 616 pp.

Aldous, D.E., Isaacs, S. and Mebalds, M.I. 1999. Endophytes in the genus Neotyphodium are not found in Australian native grasses.Australasian Plant Pathol. 28(3), I83-I86.

Andrews, J.H. 1984. Life history strategies of plant parasites. In Ingram, D.S. and Williams P.H. (eds.), Advances in Plant Pathology - Vol. 2. Academic Press, London, 303 Pp.

Andrews, J.H. 1992. Fungal life history strategies. In Carrol, G.C. and Wicklow, D.T. (eds.), the fungal community: its organization and role in ecosystem. 2nd Ed. Dekker, New York, pp. I I 9- I 46.

Andrews, J.H. and Rouse, D.I. 1982. Plant pathogens and the theory of $\boldsymbol{r}$ - and K- selection.American Nat. I20, 283-296.

Andrews, J.H. and Hirano, S.S. (eds.), Microbial Ecology of Leaves. Springer-Verlag, New-York, pp. 358-375. 
Bacon, C.W. and Williamson, J.W. 1992. Interactions of Fusarium moniliforme, its metabolites and bacteria with corn. Mycopath. I I7, 65-7I.

Bacon, C.W., Lyons, P.C., Porter, J.K. and Robbins, J.D. 1986. Ergot toxicity from endophyte-infected grasses: a review.Agron. J. 78, I06-II6.

Bacon, C.W. and Siegel, M.R. 1988. Endophyte parasitism of tall fescue. J. Product. Agricult. I, 45-55.

Barklund, P. and Unestam, T. 1988. Infection experiments with Gremmienella abietina on seedlings of Norway spruce and scots pine. Eur. J. For. Pathol. 18, 409-420.

Barret, J.A. 1983. Plant-fungus symbioses. In Futuyma, D.J. and Slatkin, M. (eds.), Coevolution. Sinauer Associates, Sunderland, Mass, pp. I37-160.

Barret, J.A. 1986. Host-parasite interactions and systematics. In Stone, A.R. and Hawskworth, D.L. (eds.), Coevolution and Systematics. Clarendon Press, Oxford, pp. I- 17

Carrol, G.C. (1988). Fungal endophytes in stems and leaves: from latent insect pathogen to mutualistic symbiont. Ecology 69, 2-9.

Carrol, G.C. 199I. Beyond pest deterrence - Alternative strategies and hidden costs of endophytic mutualisms in vascular plants.

Carrol, F.E., Müller, E. and Sutton, B.C. 1977. Preliminary studies on the incidence of needle endophytes in some European conifers. Sydowia Pp. 29, 87- 103.

Dalla Valle, E. and Zechini D'Aulerio, A. 1989. Antagonismo in vitro tra Trichoderma viride e Rhizoctonia solani isolata da Pathos. Micologia Italiana Pp. 3, 7I-76.

Dreyfuss, M. and Petrini, O. 1984. Further investigations on the occurrence and distribution of endophytic fungi in tropical plants. Botánica Helvetica Pp 94, 33-40.

Dreyfuss, M. 1989. Microbial diversity. Microbial Metabolites as sources for new drugs. Princeton Drug Research Symposia, Princeton, pp. 213

De Bary, A. 1866. Morphologie und Physiologie der Pilze, Flechten, und Myxomyceten. Vol. II. Hofmeister's Handbook of Phisiological Botany, Leipzig.

Luppi-Mosca, A.M. 1960. Sobre la micoflora del terreno de un bosque de Pinus nigra var. Laricio. An. Inst. Bot. A.J. Cavanilles Pp. 18, 91-108.

Neill, J.C. 194I. The endophytes of Lolium and Festuca. New Zealand J. Sci. Technol. pp 23, 185- 93.
Petrini, O. 198I. Fungal endophytes of tree leaves. In Andrews, J.H. and Hirano, S.S. (eds.),microbial Ecology of Leaves. Springer-Verlag, New-York, Pp. 179. 197.

Petrini, O. 1986. Taxonomy of endophytic fungi in aerial plant tissues. In Fokkema, N.J. and van den Heuvel, J. (eds.), Microbiology of the Phyllosphere. Cambridge University Press, Cambridge, pp. I75-187.

Petrini, O. and Dreyfuss, M. 198I. Endophytische Pilze in epiphytischen Araceae, Bromeliaceae und Orchidaceae. Sydowia pp. 34, I35- I 45.

Petrini, O., Fisher, P.J. and Petrini, L.E. 1992. Fungal endophytes of bracken (Pteridium aquilinum) with some reflections on their use in biological control. Sydowia pp. 282-293.

Rodrigues, K.F. (1992). Endophytic fungi in the tropical palm Euterpe oleracea Mart. Ph. D. Thesis City University of New York, Lehman College, pp. 258

Rodrigues, K.F. (1996). Fungal endophytes of palm. In Redlin, S.C. and Carras, M.L. (eds.), Endophytic Fungi in Grasses and Woody Plants. American Phytopathological Society, St. Paul, Minnesota, pp. I2I-I 32.

Rodrigues, K.F. and Samuels, G.J. (1990). Preliminary study of endophytic fungi in a tropical palm. Mycol. Res. pp. 94, 827-830.

Rodrigues, K.F. and Samuels, G.J. 1992. Species endophytic in palms. Mycotaxon 43, 27I-276.

Sridhar, K.R. and Raviraja, N.S. (1995). Endophytes - A crucial issue. Current Sci. 69, 570-57I.

Pearce, M.H. (1990). in vitro interactions between ArmiIlaria luteobubalina and other wood decay fungi. Mycol. Res. 94, 753-76I.

Varese, G.C. and Luppi-Mosca, A.M. (I99I). Funghi rizoplanici di Fagus selvatica L. e loro interazioni. Giorn. Bot. Ital. 125, 254.

Watanabe, T. (1980). A new variety of Verticillium sphaerosporum an endoparasite of nematode and its antagonism to soil-borne plant pathogens. Ann. Phytopathol. Soc. Japan 46, 598606.

Wennström, A. (1994). Endophyte: the misuse of an old term. Oikos 7I, 535-536.

Wennström, A. and Ericson, L. (1994). The effect of the systemic smut Urocystis

Wilson, R., Wheatcroft, R., Miller, J.D. and Whitney, N.J. (I995). Genetic diversity among natural populations of endophytic Lophodermium pinastri from Pinus resinosa. Mycol. Res. 98, 740-744. 